\title{
PHENOTYPIC CHARACTERIZATION OF ZINC AND IRON RICH CYTOPLASMIC MALE STERILE LINES OF RICE
}

\author{
S. Mashiat ${ }^{1}$, N. A. Ivy ${ }^{1 *}$, M. G. Rasul ${ }^{1}$, M. M. Haque ${ }^{2}$ and M. S. Raihan ${ }^{1}$
}

\begin{abstract}
A total of 23 cytoplasmic male sterile (A) lines with their corresponding maintainer (B) lines of rice were used for the experiment. The experiment was carried out in completely randomized block design with two replications in the experimental field of the Department of Genetics and Plant Breeding, Bangabandhu Sheikh Mujibur Rahman Agricultural University (BSMRAU), Gazipur during Aman season 2017. A total of 13 characters were studied. BRRI 1A, IR $62 \mathrm{~A}$ and IR $68888 \mathrm{~A}$ had shown both the earliness and dwarfness character. The higher yield per plant was obtained from Gan 46 A, Straw A, Sugundhi dhan 2A, IR 68888 A and BRRI 1A. Zinc and Iron content of phenotypically best performed rice genotypes were determined in brown condition by using X-Ray Fluorescence technique (XRF). Small differences between Genotypic and Phenotypic coefficient of variation were recorded for all the characters studied which indicated less influence of environment in expression of the characters. Correlation study revealed that selection based on weight of filled grain per panicle, thousand grain weight and number of grains per panicle would be effective for increasing grain yield per plant. Path co-efficient study showed that direct selection based on weight of filled grain per panicle and number of effective tiller per plant would be indicator for yield improvement. Considering yield and studied characters IR 58 A, IR 62 A, IR 68888 A, Gan 46 A and BRRI 1A could be used as cytoplasmic male sterile line which is enriched with zinc and iron.
\end{abstract}

Keywords: Male sterility, maintainer, zinc, iron, grain yield.

\section{Introduction}

Rice occupies the enviable prime place among cereals as this unique grain helps to sustain two thirds of the world's population. It is the second most widely consumed food grain in the world next to wheat (FAOSTAT, 2018). But beyond easing hunger pains and providing carbohydrates for energy, cultivated rice has little nutritional value. It is a poor source of essential micronutrients such as $\mathrm{Fe}(0.80 \mathrm{mg})$ and $\mathrm{Zn}(1.09 \mathrm{mg})$ per $100 \mathrm{~g}$ of rice (USDA Nutrient Database, 2016). It means many people who depend on rice as a staple food are effectively being starved of essential micronutrients. Nutritionists call it "hidden hunger". Iron deficiency is the most common nutritional disorder in the globe affecting between 2 to 5 billion people. In Bangladesh $49 \%$ of pregnant woman and $53 \%$ of preschool children are anemic due to iron deficiency (Jahan et al., 2013). It impairs immunity, reduces the physical growth and cognitive development. One-third of the human population, particularly children and women suffer from $\mathrm{Zn}$ deficiency related

\footnotetext{
${ }^{1}$ Department of Genetics and Plant Breeding, Bangabandhu Sheikh Mujibur Rahman Agricultural University, Gazipur 1706, ${ }^{2}$ Department of Agronomy, Bangabandhu Sheikh Mujibur Rahman Agricultural University, Gazipur 1706, Bangladesh. *Corresponding author: ivy.bsmrau@yahoo.com
} 
health problems such as growth retardation, loss of appetite, impaired immune function, hair loss, diarrhea, eye and skin lesions, weight loss, delayed healing of wounds, and mental lethargy (Swamy et al., 2016).

In different countries, the hybrid rice is produced by using cytoplasmic male sterility (CMS) system. CMS is a condition under which a plant is unable to produce functional pollen. Male sterile (A) line is used as female line in commercial hybrid production plot. It is also characterized by agronomical superiority, stable sterility, wide regeneration spectrum, abortive anther and highly synchronized. Plant breeding programs in biofortification of staple food crops such as rice requires screening of germplasm having $\mathrm{Fe}$ and $\mathrm{Zn}$ dense grains to be used as donor parents. Ideally, once rice is biofortified with vital nutrients, the farmer can grow indefinitely without any additional input to produce nutrient packed rice grains in a sustainable way. By using zinc and iron rich male sterile line we can easily develop hybrid rice with high zinc and iron content. Study of genotypic and phenotypic coefficient of variation help to find out the apparent variation is due to genetic or growing environment in the expression of the traits. By correlation and path analysis study, the extent of the influence of the characters on yield would be known. Keeping in view the above perspectives, the present investigation is carried out to study genetic variability, character association and characterization of the selected genotypes for choosing a desired cytoplasmic male sterile line for development of hybrid rice.

\section{Materials and Methods}

This experiment was conducted at the experimental field of Bangabandhu Sheikh Mujibur Rahman Agricultural University (BSMRAU), Gazipur during Aman season 2017. Twenty three (23) male sterile (A) line with their corresponding maintainer (B) line were used for this research (Table 1) which were collected from the Department of Genetics and Plant Breeding of BSMRAU, Gazipur. The experiment was laid out in completely randomized block design (RCBD) with two replications. The length of the plot is $30 \mathrm{~m}$ and width is $5 \mathrm{~m}$. Each entry was planted with $20 \times 20 \mathrm{~cm}$ spacing. The date of seed sowing in the seed bed was 22 July 2017. The seedlings of 21 days ages of A line were transplanted with their corresponding B line at 12 August 2017. Data on days to $50 \%$ heading, days to maturity were recorded at respective stage of crop while, plant height, effective tillers per plant, panicle length were recorded at the time of harvest and number of grains per panicle, weight of filled grain per panicle, thousand grain weight, grain length and width and grain yield per plant were recorded after harvest. The amount of zinc and iron in the grain were measured in brown condition by using X-ray Fluorescence Spectrophotometer in Laboratory of Harvest Plus, Bogura. All data obtained for the characters were statistically analyzed. Means values were separated by least significant difference (LSD). Genotypic and phenotypic coefficient of variation were calculated following the formula given by Burton (1952). For calculating the genotypic correlation coefficient for all possible combinations the formula suggested by Miller et al. (1958), Hanson et al. (1956) and Johnson et al. (1955) were adopted. Correlation 
Table 1. List of 23 cytoplasmic male sterile lines (A line) of rice

\begin{tabular}{|l|l|l|l|}
\hline A1 & IR 58 A & A13 & Khazar A \\
A2 & IR 62 A & A14 & Khutichikon A \\
A3 & IR 68888 A & A15 & Chinirri A \\
A4 & Gan 46 A BRRI 1A & A16 & Straw A \\
A5 & Dakshahi A & A17 & Begun bitchi A \\
A6 & Kalijira 12A & A18 & Rajbut A \\
A7 & Kalijira 2A & A19 & Nayon moni A \\
A8 & Dubsail A & A20 & Lalsoru A \\
A9 & Sugundhi dhan 2A & A21 & Malsire A \\
A10 & Bashmoti-IR 3643A & A22 & Raduni pagol A \\
A11 & Tilkapur A & A23 & Elai A \\
A12 & & \\
\hline
\end{tabular}

coefficients were further partitioned into components of direct and indirect effects by path coefficient analysis which was originally developed by Wright (1921 and 1923) and later described by Dewey and $\mathrm{Lu}$ (1956).

\section{Results and Discussion}

\section{Mean performance}

The mean values of all genotypes for each character are described in Table 2. The mean performance ranges from 55.3-75.3 days for $50 \%$ heading. The maximum days by Dubsail $\mathrm{A}$ and the minimum days was required by IR 58 A, IR 62A and IR 68888 A. The minimum days required for maturity was observed in the genotype IR 62 A (75.3 days) and the maximum days was for Begun bitchi A (102.3 days). The genotype BRRI $1 \mathrm{~A}$ produced the shortest plant $(72.7 \mathrm{~cm})$. IR 58 A, IR 62 A, IR 68888A and Gan 46 A also produced shorter plant which are non- significant with the shortest one. Straw A produced the tallest plant $(157 \mathrm{~cm})$. The highest number of effective tillers per plant were produced by BRRI 1A (23.3) and the lowest number of effective tillers (5.33) per plant were produced by Khazar A. The highest panicle length was observed in Dakshahi A $(30.07 \mathrm{~cm})$ and the lowest panicle length was observed in genotype BRRI 1A $(24.27 \mathrm{~cm})$. The highest number of grains (260.3) per panicle was found in Sugundhi dhan $2 \mathrm{~A}$ and the lowest one was found in IR 68888 A (69). The maximum weight of filled grains per panicle was found in Straw A $(5.2 \mathrm{~g})$ and the minimum weight observed in Malsire A (1.03g). The maximum thousand grain weight was found in Straw A $(26.49 \mathrm{~g})$ and the minimum thousand grain weight was found in Malsire A $(0.89 \mathrm{~g})$. The lowest grain length was observed in Begun bitchi A $(5.3 \mathrm{~mm})$ and the highest grain length was observed in Elai A $(11.7 \mathrm{~mm})$. The lowest grain width was recorded in Begun bitchi A $(1.1 \mathrm{~mm})$ and the highest grain width was observed in IR $62 \mathrm{~A}(2.03 \mathrm{~mm})$. The highest grain yield per plant was observed in the genotype Gan 46 A (38.43g) followed by Straw A (35.7g) and Sugundhi dhan 2A (33.64g). The lowest grain yield per plant was observed in Khazar A (7.64g). 


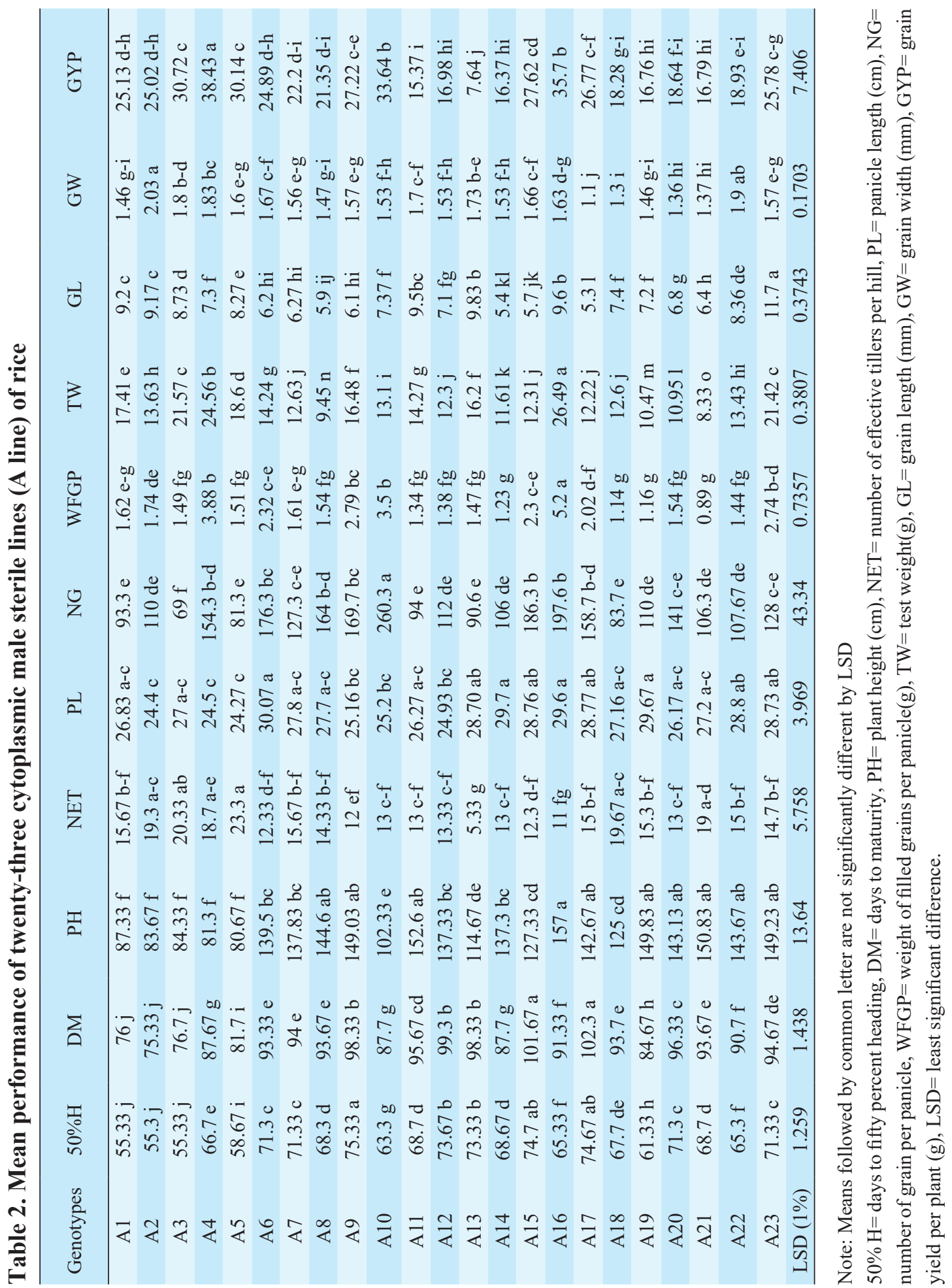


By studying the all characters, IR 58 A, IR 62 A, IR 68888 A, Gan 46 A and BRRI 1A genotypes were the best to select as male sterile line for hybrid production of rice as they have good yield and dwarf in nature. Though Straw A, Sugundhi dhan 2A, Chinirri $\mathrm{A}$ and Dubsail A having good yield but due to their long plant height, they were not selected as best male sterile line, as dwarfness is preferable for female parent. The zinc and iron content of the best selected male sterile line was measured and presented in Figure 1. Zinc content was found between $39.50 \mathrm{ppm}$ to $48.60 \mathrm{ppm}$ and iron content was found between $16.10 \mathrm{ppm}$ to $52.90 \mathrm{ppm}$ among the best selected varieties. Exceptionally high iron content was observed in BRRI 1A which should be studied further.

\section{Genetic variability}

Genotypic, phenotypic and environmental variance $\left(\sigma^{2} \mathrm{~g}, \sigma^{2} \mathrm{p}\right.$ and $\left.\sigma^{2} \mathrm{e}\right)$, coefficient of variation (GCV and $\mathrm{PCV})$, heritability in broad sense $\left(h^{2} b\right)$, genetic advance (GA) and GA in percent of mean are presented in Table 3 . The high degree of genotypic variation indicated preponderance of additive gene effects. Genotypic and phenotypic variances were much pronounced for $50 \%$ heading, days to maturity, plant height, number of grains per panicle and thousand grain weight indicating greater scope of selection for the improvement of these traits. Minimum genotypic and phenotypic variances were observed for rest of the traits. The differences between GCV and PCV were higher for number of effective tillers per plant, panicle length, number of grains per panicle and weight of filled grain per panicle indicating environmental influence of these traits. Minimum differences between GCV and PCV were observed for rest of the traits. Close value of GCV and PCV indicated that majority portion of the phenotypic variances was genetic in nature i. e., less environmental influence for these traits. Heritability in broad sense $\left(h^{2} b\right)$ was high for

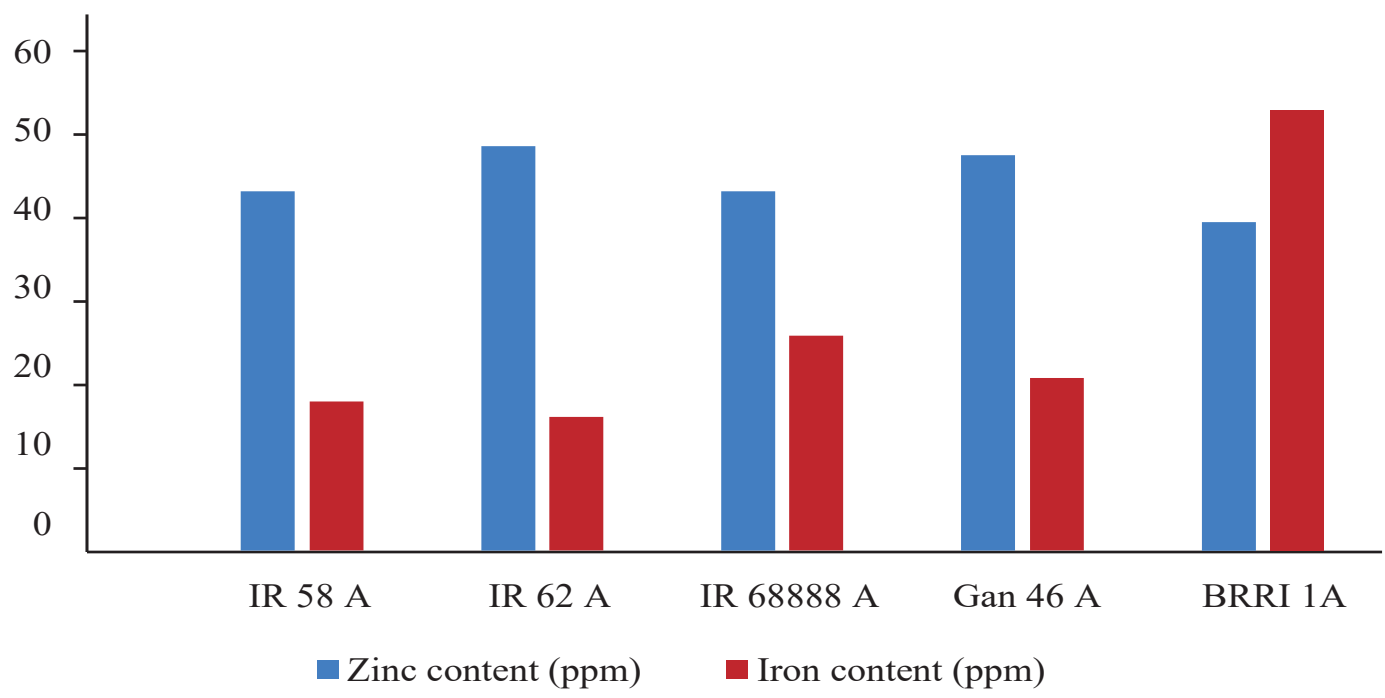

Fig. 1. Graphical representation of zinc and iron content of five cytoplasmic male sterile lines of rice. 


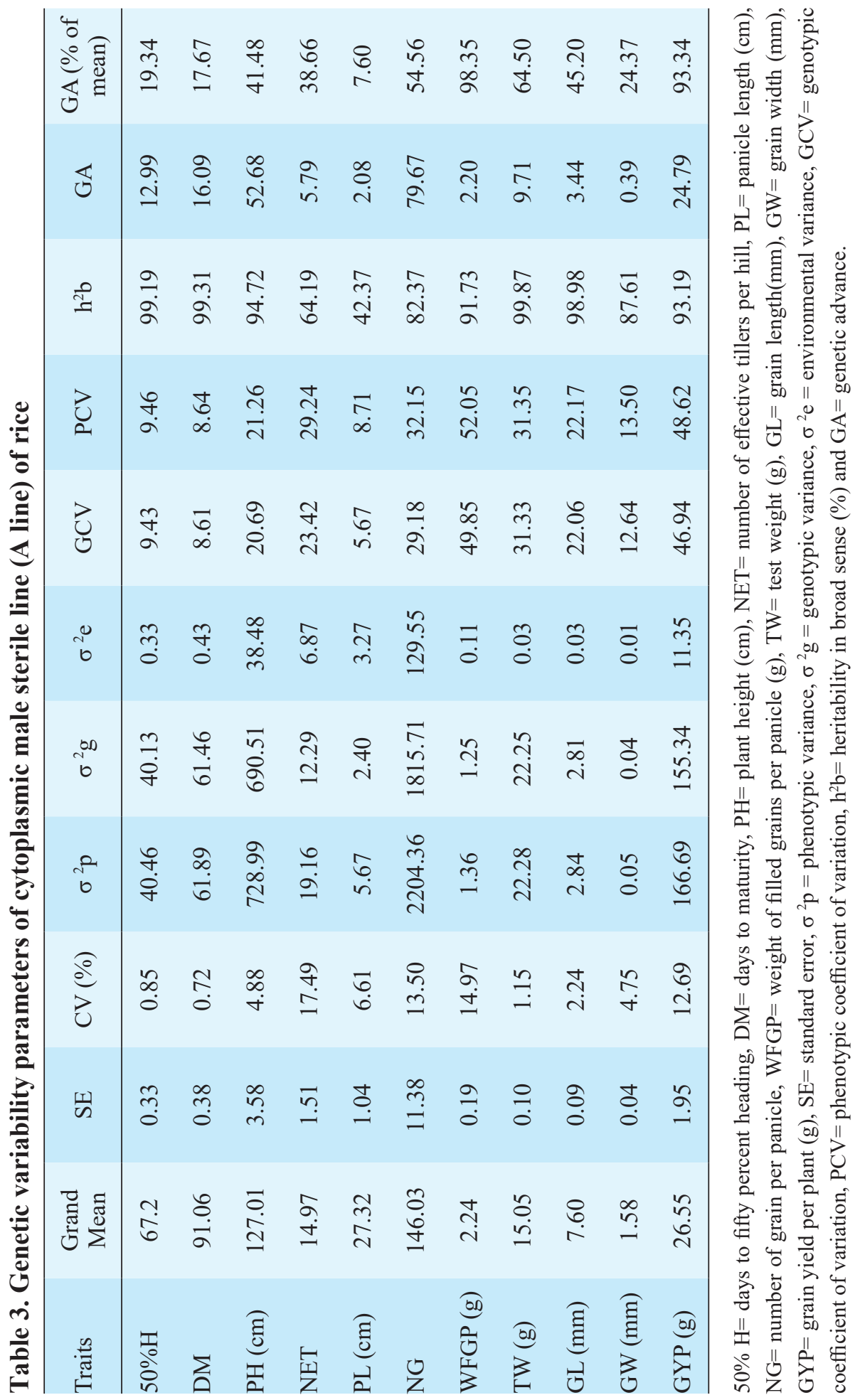


all the traits except number of productive tillers per plant and panicle length. High GA and GA in percent of mean were observed for number of grains per panicle indicated that the trait could be improved through selection and had additive gene action.

\section{Character association}

Genotypic correlation coefficients $(\mathrm{rg})$ for all the traits are shown in Table 4. Fifty percent heading showed the highest significant positive genotypic correlation with days to maturity. Days to maturity along with fifty percent heading showed the highest significant negative genotypic correlation with number of effective tillers per hill. Plant height showed the highest significant positive genotypic correlation with panicle length and the highest significant negative genotypic correlation with grain yield per plant. Number of effective tillers per plant showed significant positive genotypic correlation with grain yield per plant and significant negative genotypic correlation with panicle length. Number of grain per panicle showed highest significant positive genotypic correlation with weight of filled grain per panicle and grain yield per plant. Weight of filled grains per panicle showed highest significant positive genotypic correlation with thousand grain weight and grain yield per plant. Thousand grain weight showed significant positive genotypic correlation with grain yield per plant. Grain length showed significant positive genotypic correlation with grain width.

\section{Path co-efficient analysis}

In the present investigation grain yield per plant was considered as a resultant variable and
$50 \%$ heading, days to maturity, plant height, number of effective tillers per hill, panicle length, number of grains per panicle, weight of filled grain per panicle, thousand grain weight were causal (independent) variables (Table 5). Weight of filled grains per panicle exhibited the highest positive direct effects. Days to maturity exhibited the lowest positive direct effects. Thousand grain weight exhibited the highest negative direct effects but positive indirect effects via most of the traits led them to significant positive correlation with grain yield per plant. Number of grain per panicle exhibited the lowest negative direct effects but positive indirect effects via most of the traits led them to significant positive correlation with grain yield.

The residual effect was 0.07 indicated that only $93 \%$ of the variability observed for grain yield was represented by 11 traits studied. Therefore, $7 \%$ variability represented by other traits that was not included in this experiment which might be also have major role in determination of grain yield of the rice.

\section{Conclusions}

The highest mean performance for yield in male sterile lines was found in genotype Gan 46 A followed by Straw A and Sugundhi dhan 2A. For earliness and dwarfness, BRRI 1A, IR 62 A and IR 68888 A can be selected. Regarding yield and studied characters IR 58 A, IR 62 A, IR 68888 A, Gan 46 A and BRRI 1A could be used as cytoplasmic male sterile line which is enriched with zinc and iron. Grain yield per plant was highly significantly and positively correlated with weight of filled grains per panicle at genotypic levels. Highly significant and positive inter 


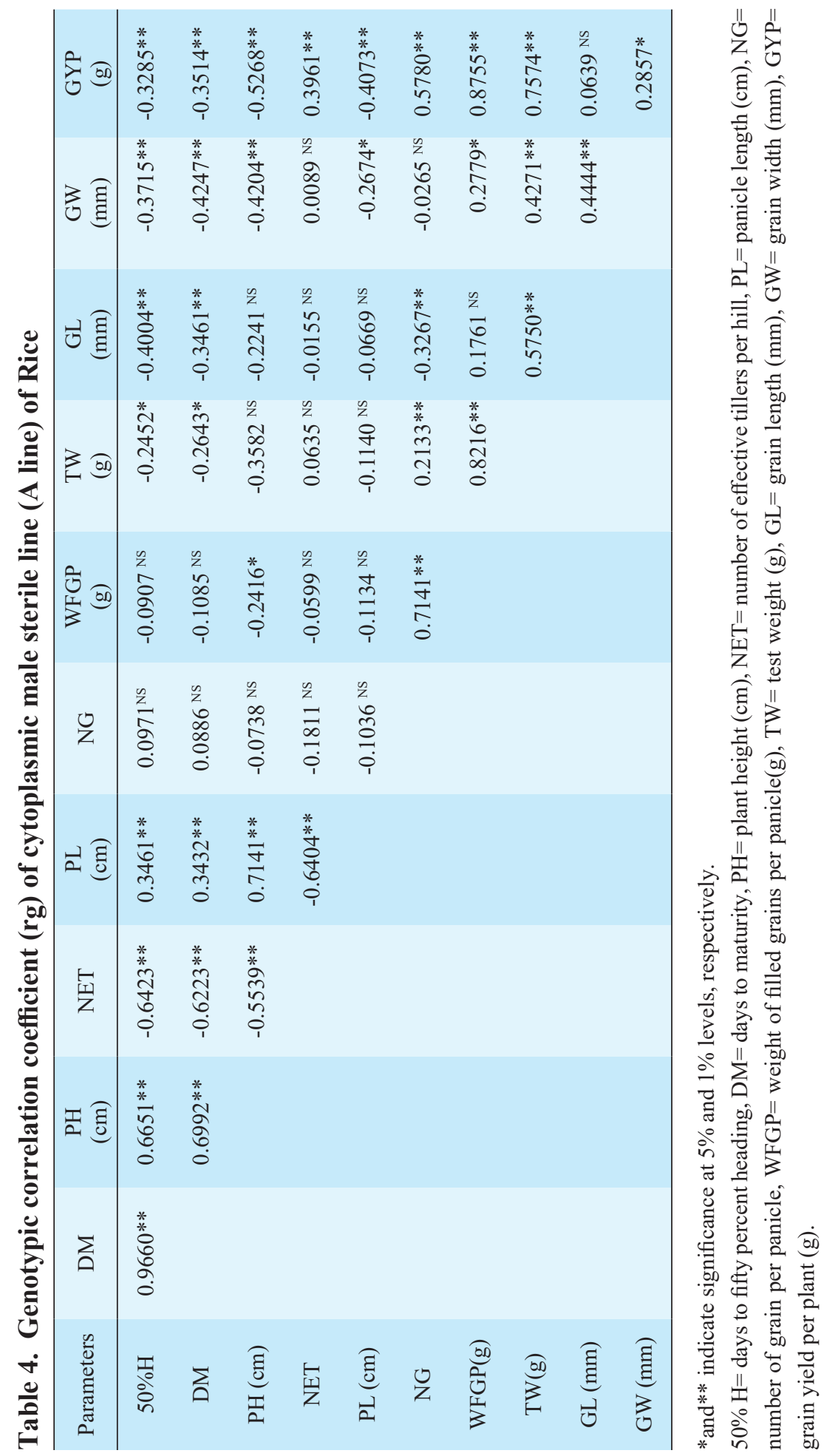




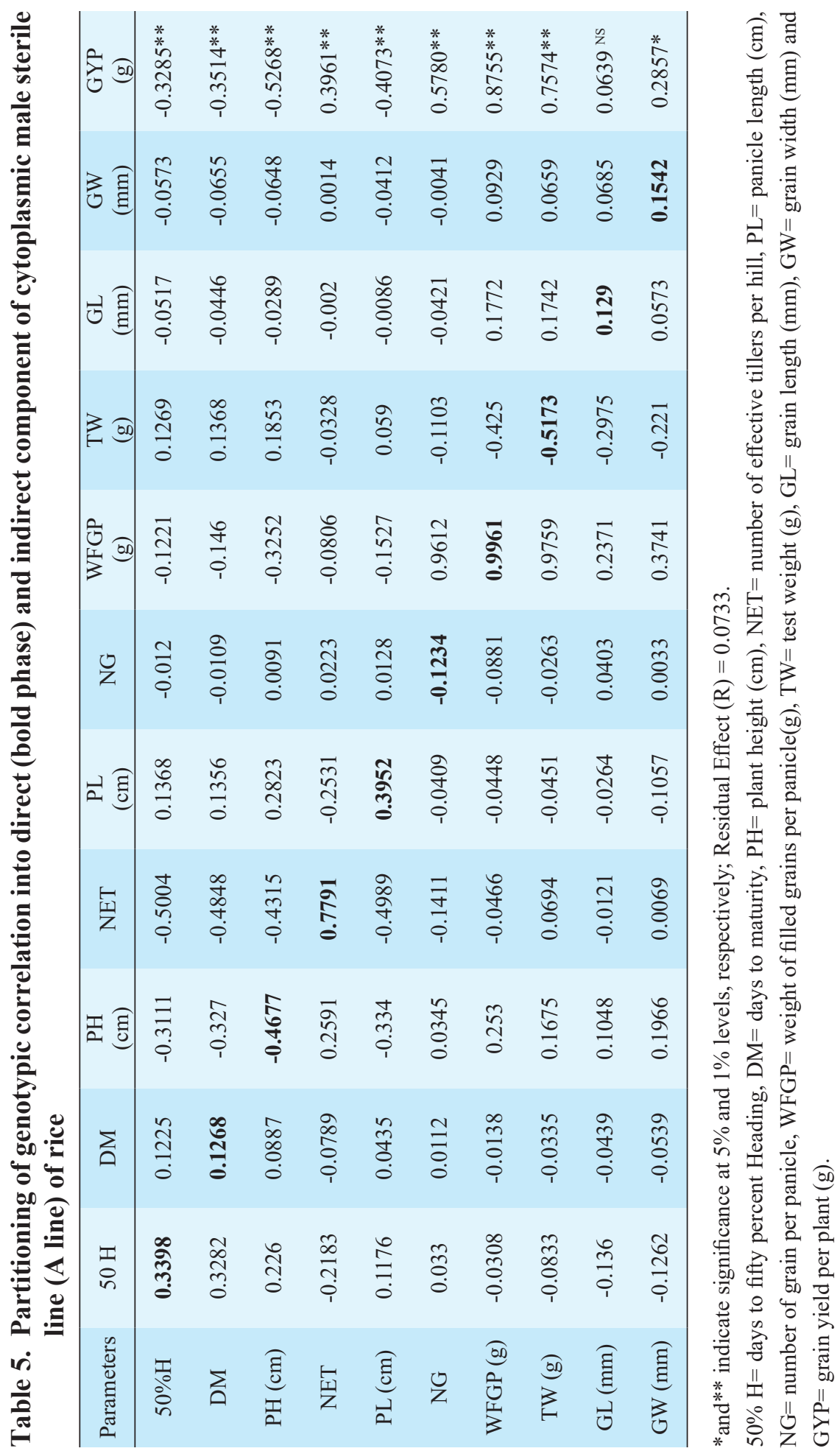


character association at genotypic levels were obtained between days to maturity vs. fifty percent heading. Correlation study revealed that selection based on weight of filled grain per panicle, thousand grain weight and number of grains per panicle would be effective for increasing grain yield per plant. The results of path coefficient analysis revealed that weight of filled grain per panicle had the highest positive direct effect on grain yield per plant followed by number of effective tiller per plant.

\section{Acknowledgements}

The project was funded by the Research Management wing (RMW), BSMRAU, Gazipur. The authors are grateful to Mohammed Harun or Rashid, Senior Scientific Officer, Oilseed Breeding, Bangladesh Agricultural Research Institute, Gazipur for his kind assistance and valuable advice for conducting research work.

\section{References}

Burton, G. W. 1952. Quantitaive inhereitance in grasses. Proc. 6th Intercropping. Grassland Cong. 1: Chowdhury, N. H. 1991. Studies on quality of rice in Bangladesh. In: Proceeding of the workshop on chemical aspects of rice grain quality, IRRI, Philippines. Pp. 23-127.
Dewey, D. R. and K .H. Lu. 1959. A correlation and path coefficient analysis of components of crested wheat grass production. Agronomy Journal, 52: 515-518.

Hanson, C. H., H. F. Robinson and R. E. Comstock. 1956. Biometrical studies of yield in segregating populations of Korean Lespedza. Agronomy Journal 48: 268-272.

Jahan, G. S., L. Hassan, S. N. Begum and S. N. Islam, 2013. Identification of iron rich rice genotypes in Bangladesh. Journal of Bangladesh Agricultural University, 11(1): 73-78.

Johnson, H. W., H. F. Robinson and R. E. Comstock. 1955. Estimates of genetic and environmental variability in soybean. Agronomy Journal, 47: 314-318.

Swamy, B. P. M., M. A. Rahman, M. A. InabanganAsilo, A. Amparado, C. Manito, P. ChadhaMohanty, R. Reinke and I. H. Slamet-Loedin. 2016. Advances in breeding for high grain Zinc in Rice. 9(1): 49.

United States Department of Agriculture. 2016. Nutrient data laboratory.

United Nations Food and agriculture organization, corporate statistical database (FAOSTAT). (2018). Crops/Regions/World list/Production Quantity (pick lists), Rice (paddy).

Wright, S. 1921. Correlation and Causation. Journal of Agricultural Research, 20: 557-587. Wright, S. 1923. Theory of path coefficient. Genetics. 8: 239-255. 